\title{
DOS OBJETIVOS AO SURGIMENTO DE UMA INOVAÇÃO SOCIAL: UM ESTUDO DE CASO EM UMA ORGANIZAÇÃO DA ECONOMIA SOLIDÁRIA
}

\author{
Anderson Sasaki Vasques Pacheco \\ Maria João Santos \\ Karin Vieira da Silva \\ Andressa Sasaki Vasques Pacheco
}

\begin{abstract}
Resumo
A presente pesquisa tem como objetivo identificar quais são os parâmetros que caracterizam ações de inovação social em uma organização da economia solidária e quais os motivos do surgimento desse tipo particular de inovação. $\mathrm{O}$ ato de identificar e caracterizar uma inovação social permite aos seus participantes uma visão mais aclarada a respeito do assunto, dando subsídios para que novos empreendimentos nesse sentido possam surgir, além de contribuir para pesquisadores que queiram compreender as inovações sociais na prática. Com relação aos procedimentos metodológicos, essa é uma investigação aplicada, pois analisa um estudo de caso em uma organização da economia solidária da área da saúde. Os dados foram coletados por meio de entrevistas semiestruturadas com os atores internos do Saúde Criança Florianópolis e pela observação participante dentro da organização, sendo que ambas foram tratadas pelo método de análise de conteúdo. Como principais resultados, observou-se que a o Plano de Ação Familiar do Saúde Criança, é uma inovação social, pois contempla os princípios de satisfação das necessidades humanas, empoderamento, mudanças de relações sociais de poder e a inclusão social. Também se verificou que o contexto de nascimento da inovação pode ser social, econômico, existencial, ambiental e político, e que ela surge no meio de uma inquietação relacionada com algum problema existente no território em que a inovação está inserida.
\end{abstract}

Palavras-chave: Inovação Social; Economia Solidária; Saúde Criança Florianópolis.

\section{FROM THE OBJECTIVES TO THE EMERGENCE OF A SOCIAL INNOVATION: A}

\section{CASE STUDY IN AN ORGANIZATION OF THE SOLIDARITY ECONOMY}

\begin{abstract}
The present research aims to identify which parameters defines a social innovation in an organization of the solidarity economy and what are the reasons for the emergence of this particular type of innovation. The act of identifying and characterizing a social innovation gives, its participants, a clearer view of the subject and subsidies new ventures. Also, this investigation contributes for researchers who want to understand social innovations in practice. Regarding the methodological procedures, this is an applied research, which analyze a case study in an organization of the solidarity economy in the health area. Data were collected through semistructured interviews with internal actors of Saúde Criança Florianópolis and by participant observation. Both were treated with content analysis method. As the main results, it was observed that the Action Plan is a social innovation, since it contemplates the principles of satisfaction of human needs, empowerment, power changes in social relations and social inclusion. It has also been found that the birth context of innovation can be social, economic, existential, environmental and political, and that it arises in the middle of a concern related to a common problem in the territory where innovation is inserted.
\end{abstract}

Keyword: Social Innovation; Solidarity Economy; Saúde Criança Florianpolis.

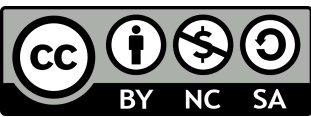




\section{INTRODUÇÃO}

Face a conjuntura de recessão econômica e social que afeta diversos países, o (re)surgimento de organizações orientadas pela igualdade e solidariedade se torna presente, em reposta à falência dos Estados Sociais e ao descompromisso crescente dos mercados com a sociedade (COUTO, SANTOS, GUERRA; 2012). No Brasil, a denominação economia solidária está presente desde a década de 80 (GAIGER, 2007; COUTO ET AL., 2012), oriundas da necessidade de enfrentamento de lacunas sociais não atendidas pelo Estado e nem pelo mercado. Ao nível europeu, o fortalecimento dessas iniciativas possui origem semelhante e vinculada, principalmente, à crise econômica e social que a Europa enfrenta atualmente.

\footnotetext{
Em períodos de crises, as regras macro-sociais (mercado, Estado e arranjos coletivos) são abalados, desta maneira criando mais espaços para a inovação e experimentação. Novas normas, valores, e regras são originadas através da relação entre atores sociais, bem como através de experiências locais que estendem a toda a sociedade. (BOUCHARD, 2011, p. 49-50).
}

Nesse âmbito surge a economia solidária, aliada a novos modelos de desenvolvimento alternativo, e constituindo-se, de certa forma, como um novo capítulo da economia social (LAVILLE, 2014).

As organizações da economia solidária referem-se a um conjunto de empreendimentos que buscam responder a certos problemas locais específicos. O termo "economia solidária" tem o objetivo "num primeiro momento, indicar, por um lado, a associação de duas noções historicamente dissociadas, isto é, iniciativa e solidariedade; e, por outro lado, sugere-se (com estas experiências) a inscrição da solidariedade no centro mesmo da elaboração coletiva de atividades econômicas" (FRANÇA FILHO, 2001, p.248).

Os propósitos que orientam essas organizações apresentam interface próxima com a perspectiva da inovação social (IS), pois ambas estão voltadas para o enfrentamento de demandas sociais e possuem potencial para o desenvolvimento de novas relações entre a sociedade, o mercado e o Estado, focando no protagonismo das comunidades nesta relação (NESTA, 2014; YOUNG FOUNDATION, 2010; MURRAY, CAULIER-GRICE, MULGAN, 2010). Este tipo de inovação apresenta-se como um forte catalizador do desenvolvimento de organizações de cunho social, pois oferece novas alternativas de estruturação, de produtos e de relacionamento entre as esferas da sociedade.

Assim, pode-se dizer que a economia solidária tem contribuído para o desenvolvimento de inovações sociais (NEAMTAM, 2002). Como salienta Bouchard (2011), ela é um 
laboratório para inovações sociais, que busca, em conjunto com outros atores, desenhar planos para uma economia que não está desconectada nem do social nem da esfera política.

Corroborando o fato da economia solidária ser um laboratório para inovações sociais, Costa e Carrion (2009) salientam que esse tipo de economia, embora longe de constituir um modelo utópico ou um modelo acabado de comportamento democrático ideal, apresenta-se como laboratório de práticas, de experimentação de processos sócio-político inovadores. Deste modo, justifica-se um aprofundamento da análise dos processos de inovação neste universo particular, não apenas pelo valor fundamental das transformações que corporiza, mas também pela especificidade que possui.

Tendo em vista que as organizações da economia solidária são laboratórios de inovações sociais e a carência de delimitações teóricas sobre os conceitos trabalhados anteriormente, julgamos importante compreender como a inovação social é desenhada em empreendimentos de economia solidária.

Dessa forma, as perguntas norteadoras desse artigo são: "Quais são os parâmetros para que uma atividade da economia solidária possa ser considerada uma inovação social?" e "Quais são os fatores que fazem surgir as inovações sociais?" Os objetivos da pesquisa são, portanto, identificar os parâmetros para que a atividade da economia solidária possa ser considerada uma inovação social e identificar os fatores de surgimento de uma inovação social. Ressalta-se que a os fatores de identificação de uma inovação social não ficarão somente no âmbito teórico sendo apresentado um estudo de caso para demonstrar os aspectos de surgimento e de definição desse tipo particular de inovação.

A ação de identificar inovações sociais é importante, sobretudo, por dois motivos; primeiramente, essa pesquisa é relevante, pois auxilia os diversos atores de organizações da economia solidária a desenvolverem inovações sociais, baseadas nos preceitos teóricos norteadores do campo. Além disso, a investigação ampara também novos pesquisadores que queiram adentrar e contribuir para os estudos em inovação social, pois com a identificação de inovações sociais, será possível desenvolver novas pesquisas que possam revelar novos aspectos, tais como o impacto dessas inovações para o território.

Desta forma, para atingir os referidos objetivos, a pesquisa foi separada em quatro capítulos, além dessa introdução. Primeiro, falaremos sobre os aspectos teóricos da inovação social para compreender como podemos identificá-la. No segundo capítulo, apresentaremos os métodos aplicados neste trabalho. No terceiro capítulo abordaremos um exemplo de inovação 
social da economia solidária na área da saúde. Por fim, apresentaremos as considerações finais do artigo e novos rumos para as próximas pesquisas.

\section{INOVAÇÃO SOCIAL}

A designação inovação social não é nova, tem sido utilizada em diferentes contextos, algumas vezes pejorativos, outras com conotações positivas. Pode-se dizer que uma expressão similar, invenções sociais, foi cunhada por Max Weber no século XIX e reproduzida por Joseph Schumpeter, em 1930. Outros termos, tais como mudança, transformação, ou regulação social (Weber e Durkheim) e difusão social (TARDE, 1999 [1893]), eram tratados também como uma definição de inovação social (MOULAERT, NUSSBAUMER, 2006; JESSOP et al., 2013).

As primeiras definições, que perduraram até a década de 70, tratavam as "invenções sociais" como um constructo teórico para explicar as mudanças que rompiam com algum período da sociedade que, consequentemente, transformavam aspectos culturais, econômicos e sociais. Como exemplo, poderíamos citar a revolução industrial, que modificou o sistema econômico e social na época (JESSOP et al., 2013).

Portanto, a terminologia inovação social não era muito utilizado no âmbito das ciências sociais, sendo que as expressões invenções sociais e mudança sociais eram mais corriqueiras nos estudos acadêmicos (MOULAERT, NUSSBAUMER, 2006; BEPA, 2011). O termo inovação social, tal como o conhecemos hoje, passou a ter relevância na academia com os trabalhos de Taylor (1970) e Gabor (1970). Para o primeiro autor, a inovação social representa uma nova maneira social de se desenvolver algo, como, por exemplo, uma escola inovadora, uma nova maneira de lidar com a pobreza, um novo procedimento para (re)socializar as pessoas. Já Gabor, entende a inovação social como uma ferramenta de resolução de problemas do território (CLOUTIER, 2003).

Desta forma, se contarmos que as expressões mudança social e invenções sociais são precursoras nos estudos sobre inovação social, pode-se dizer que, num primeiro momento, inovações sociais eram utilizadas como argumento para o debate em torno da transformação da sociedade. Sendo, particularmente, o caso dos argumentos da ciência política acerca do papel da sociedade civil na mudança social e no contexto das dinâmicas macroeconômicas globais (MOULAERT et al., 2005). Posteriormente, em particular nos anos 90, e no rescaldo das crises econômicas, o tema ganha terreno surgindo associado ao aparecimento de dinâmicas 
econômicas e sociais que ultrapassam a esfera da economia de mercado e se relacionam, em particular, com o crescimento da economia social. (MOULAERT et al., 2005).

Nesta última perspectiva, considera-se que organizações sociais geram processos de inovação social distintos, nomeadamente por comparação com uma concepção de inovação considerada numa lógica economicista, devendo, por isso, ser considerada na sua especificidade própria, de complexidade e diferenciação. As investigações em curso (MOULAERT, AILENEI, 2005; BOUCHARD, 2011) não excluem os aspectos econômicos na análise, mas também consideram que enfatizar em exclusivo este âmbito de análise pode facilmente levar uma interpretação reducionista do conceito e, consequentemente, reduzir o potencial explicativo dos processos de inovação, nomeadamente a vertente social (BIGNETTI, 2011; JESSOP et al., 2013).

Atualmente a expressão inovação social não visa somente a mudança social, mas abrange diversas compreensões, dependendo da perspectiva teórica em que ela é estudada. Diversos autores também separam de diferentes maneiras as visões existentes da inovação social na academia. Cloutier (2003), um dos primeiros autores a fazer essa separação, separa os estudos em inovação social em: a) inovações centradas no indivíduo; b) inovações orientadas sobre o meio; c) inovações no seio das empresas.

Para Bouchard (2011) existem duas correntes existentes, a filantrópica e a processual coletiva; Moulaert et al. (2005) separa em quatro fios condutores, I) as ciências da administração e economia, II) estudos em artes e criatividade, III) ciência política e administração pública participativa, e IV) desenvolvimento local. Crises (2015), o principal centro de pesquisa em inovação social, analisa as inovações sociais por meio de três dimensões o território, condições de vida e trabalho e emprego.

O primeiro autor brasileiro a fazer uma divisão desse tipo foi Bignetti (2011) separa por locais onde eclodem a inovação social, quais sejam no empreendedorismo social, em empresas e nos movimentos sociais. Há também separações pelos resultados e formas de difusão Dees, Anderson e Wei-Skillern (2004) e pelas dinâmicas inerentes ao seu desenvolvimento e à sua aplicação (MULGAN et al. 2007).

Nesta pesquisa, como o enfoque está em analisar os aspectos da inovação social em organizações da economia solidária, utilizaremos o pensamento de Moulaert et al. (2005) e de Bouchard (2011). No primeiro autor, os estudos sobre o desenvolvimento local serão os norteadores, e no pensamento de Bouchard (2011) o movimento de pesquisas do campo 
processual coletivo apresentam-se como os que tem uma melhor aproximação dos preceitos da economia solidária.

\subsection{O objetivo e o contexto de nascimento de uma inovação social}

Os estudos do desenvolvimento local e territorial e da administração pública podem ser vistos como linhas que separam as características de eficiência e eficácia da inovação social. Portanto, para essas correntes, o objetivo da IS é servir os membros e a comunidade por emergir como resposta as aspirações coletivas e por corresponder aos valores de equidade e justiça social (BOUCHARD, 2011). Para que isso aconteça, segundo Moulaert (2005), Moulaert et al. (2005) e André e Abreu (2006), ela deve responder aos seguintes anseios: 1) contribuir para a satisfação das necessidades humanas antes não satisfeitas, seja pelo mercado ou pelo Estado; 2) colaborar para o acesso aos direitos (ex: inclusão política, políticas públicas redistributivas, etc); 3) aprimorar as capacidades humanas (ex: empoderar grupos sociais, etc).

Em relação ao objeto de estudo, a linha do desenvolvimento territorial destaca a estrutura social catalizadora que fomenta a participação, promoção da inclusão social e empoderamento de atores antes excluídos da sociedade através de movimentos sociais, organizações sociais, assim como políticas públicas (MOULAERT, 2009, 2010).

Uma tentativa de ilustrar o funcionamento de uma inovação social, desde sua criação e objetivo, até a sua maturidade, foi construída no modelo ALMOLIN, ALternative MOdel of Local INnovation (modelo alternativo de inovação local) apresentado em diversos projetos e estudos (MOULAERT et al., 2005; MOULAERT, 2009; GONZALEZ et al., 2010). Este modelo interdisciplinar foi criado usando elementos de diferentes campos das ciências sociais, nomeadamente a teoria crítica do Estado, sociedade civil, comunidade, bairros de habitação, desenvolvimento, organização, economia social e participação. Em conjunto, estas teorias permitem a compreensão da inovação social no desenvolvimento local, particularmente naquelas que surgiram em resposta a processos de alienação, exploração e exclusão de diferentes atores.

Desta maneira, o modelo ALMOLIN analisa as dinâmicas da inovação social representando-as na Figura 1 desta pesquisa. 
Figura 1 - Dinâmicas da Inovação Social do modelo ALMOLIN.

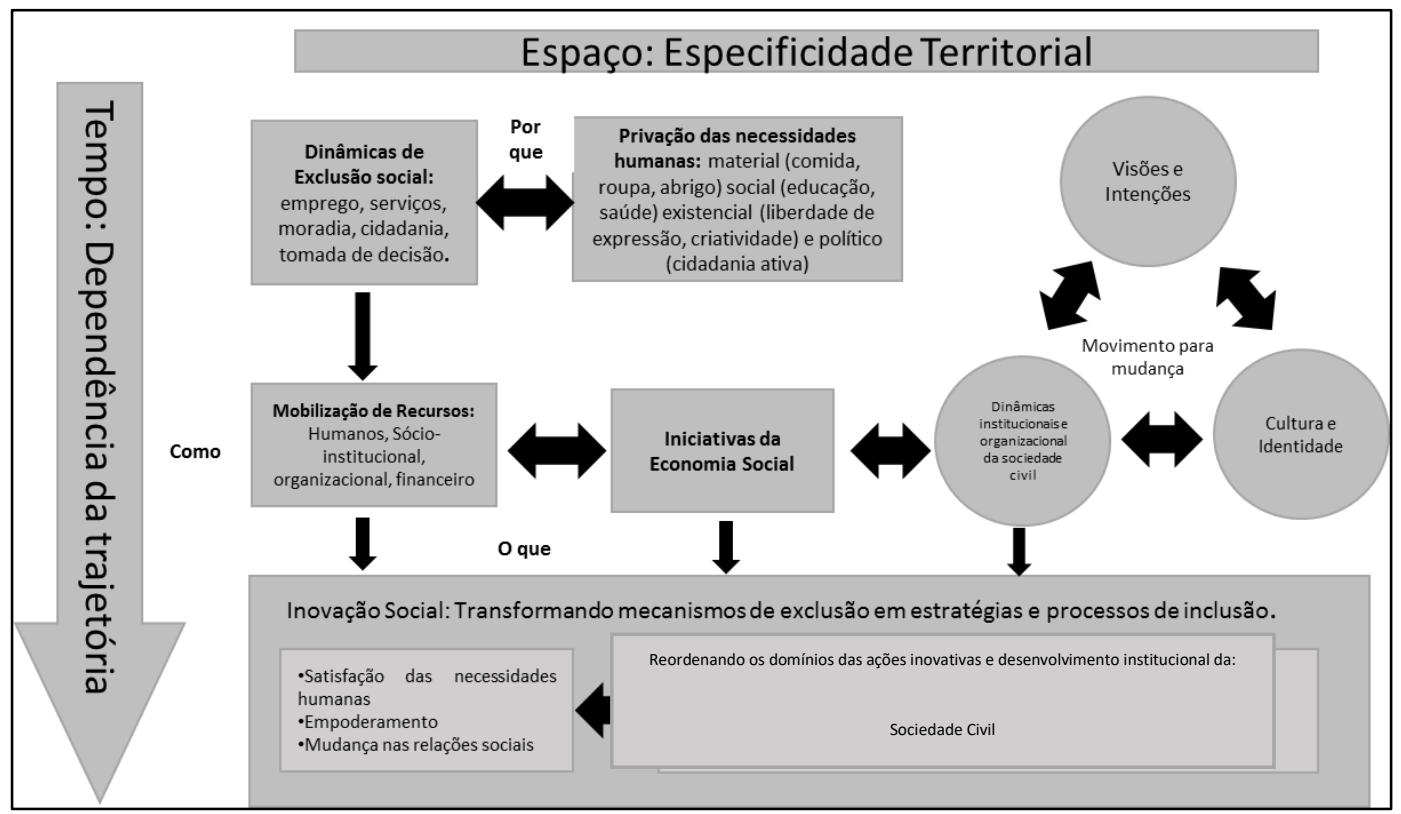

Fonte: Gonzalez et al. (2010, p. 52).

$\mathrm{Na}$ parte exterior da Figura 1, a influenciar todas as outras atividades, estão as dimensões espaciais e temporais. Enraizadas nas teorias holística, exclusão/inclusão social, dependência da trajetória, economia social e espaço e território da geografia, as dimensões representam o aspecto local das inovações sociais e o caráter de transição temporal que elas possuem em cada região (GONZALEZ et al., 2010).

No centro do modelo está a dinâmica entre exclusão social e privação das necessidades humanas, que são combatidas através das dinâmicas de inovação social. Essas dinâmicas, reagem contra a exclusão, muitas vezes, em forma de movimentos sociais, numa cultura de mudança em busca de uma nova identidade, cultura e visão para a supressão da alienação e humilhação do ser (GONZALEZ et al., 2010).

Na parte inferior da Figura 1, o modelo mostra como as inovações sociais mobilizam recursos visando a satisfação das necessidades humanas, empoderar indivíduos e mudar as relações sociais no território entre a sociedade civil, Estado e o mercado (GONZALEZ et al., 2010).

Dessa forma, pode-se verificar, novamente, quais são os preceitos e valores relacionados com uma inovação social, ou seja, seu objetivo. De novo, a satisfação humana, o empoderamento, a inclusão social e as mudanças nas relações sociais são relevantes para que seja possível classificar algo como uma inovação social (GONZALEZ et al., 2010). 
Além desse aspecto, o modelo ALMOLIN também evidencia os porquês do nascimento de uma inovação social. Para os autores, as dinâmicas de exclusão social, como emprego, serviços, moradia, cidadania e tomada de decisão, são fatores relevantes para o surgimento de inovações que visam acabar com essas dinâmicas. Além disso, a privação de necessidades humanas, como material (comida, roupa e abrigo), social (educação e saúde), existencial (liberdade de expressão e criativa) e política (cidadania ativa) são elencados como aspectos que fazem surgir inovações sociais (GONZALEZ et al., 2010).

Portanto, uma inovação social nasce por diferentes contextos inciais, como sociais, econômicos, existenciais, políticos e, também, pode-se refletir que os aspectos ambientais também catalizam o surgimento desse tipo particular de inovação. Com base nessas informações, do contexto inicial de uma inovação social e, nos objetivos da inovação social, construiu-se o quadro de análise para verificar essas dimensões.

Quadro 1 - Quadro de análise para o processo descritivo da inovação social no eixo do desenvolvimento local e da ciência política.

\begin{tabular}{|c|c|c|}
\hline \multirow{4}{*}{ Objetivo (Por que?) } & $\begin{array}{l}\text { Satisfação das } \\
\text { necessidades humanas }\end{array}$ & \multirow{4}{*}{$\begin{array}{l}\text { Qual o objetivo da inovação social? Ela procura } \\
\text { atender os critérios elencados? }\end{array}$} \\
\hline & $\begin{array}{l}\text { Empoderar atores } \\
\text { excluídos e privados de } \\
\text { certos bens }\end{array}$ & \\
\hline & $\begin{array}{l}\text { Mudar as relações sociais } \\
\text { de poder }\end{array}$ & \\
\hline & Inclusão Social & \\
\hline \multirow{5}{*}{$\begin{array}{l}\text { Contexto Inicial (Por } \\
\text { que?) }\end{array}$} & Social & \multirow{5}{*}{$\begin{array}{l}\text { Quais são os contextos iniciais para o nascimento da } \\
\text { inovação social? }\end{array}$} \\
\hline & Econômico & \\
\hline & Existencial & \\
\hline & Ambiental & \\
\hline & Político & \\
\hline
\end{tabular}

Fonte: Elaborado pelos autores.

Após a definir dos aspectos teóricos referentes ao surgimento e objetivos da inovação social, a próxima seção irá abranger como foram coletados e analisados os dados que foram guiados por esse quadro.

\section{METODOLOGIA}

Quanto ao método de pesquisa, optou-se por utilizar o estudo de caso. Segundo Yin (2010) o estudo de caso é um método de pesquisa que pode ser usado em muitas situações, tais 
como para contribuir com o conhecimento de fenomenos individuais, grupais, organizacionais, sociais, políticos e relacionais. O objetivo de se usar o método de estudo de caso surge com o desejo de entender os fenômenos sociais complexos.

A segunda classificação metodológica relaciona-se às abordagens quantitativas e qualitativas de investigação. Nesta pesquisa, os dados foram predominantemente qualitativos. De acordo com a perspectiva qualitativa, um fenômeno pode ser melhor compreendido no contexto em que ocorre e do qual é parte, devendo ser analisado segundo uma perspectiva integrada. O pesquisador vai a campo para captar, de certa forma, o fenômeno a partir da perspectiva dos atores envolvidos, considerando todos os pontos de vista relevantes (GODOY, 1995).

No âmbito da organização, delimitamos o nosso objetivo de estudo na análise de inovações sociais promovidas por elas. Especificamente, na primeira organização, analisamos o Plano de Ação Familiar (PAF) e do Saúde Criança Florianópolis (SCF), após o ano de 2008. O PAF é uma metodologia de inclusão social criada para inserir famílias em situação de risco de pobreza e doença no território. Vale destacar que, em alguns momentos, principalmente sobre a criação da inovação social, analisamos o PAF e o SCF em conjunto com a criação do Saúde Criança Matriz. Isso aconteceu pela influência que a Matriz teve nos passos da organização de Florianópolis.

A análise do processo descritivo tem como objetivo retratar as características da inovação social, ou seja, seu objetivo e o contexto de nascimento. A obtenção desses dados aconteceu entre março e maio de 2015. No total, utilizamos três ferramentas para a recolha dos dados: a) entrevista semi-estruturada; b) observação; c) análise documental.

a) A entrevista semi-estruturada. Colocada por Richardson (2007) como entrevista guiada, é utilizada, particularmente, para descobrir que aspectos de uma determinada experiência, produzem mudanças nas pessoas a ela expostas. O pesquisador conhece previamente os aspectos que deseja pesquisar e com essas informações cria um guia, que pode ser alterado conforme o rumo da entrevista. Esta pesquisa contou com o trabalho de sete colaboradores que atuavam diretamente nas atividades do Saúde Criança Florianópolis, sendo alguns desses voluntários. As entrevistas foram registradas com o auxílio de um gravador digital, mediante a autorização de cada entrevistado e teve duração aproximada de uma hora.

b) Observação. Outra técnica utilizada foi a observação. Vale destacar que a observação, naturalmente, não é simplesmente o olhar, e, sim, destacar um conjunto caracterizando-o a partir de referencial teórico eleito previamente. Observar um fenômeno 
social significa separá-lo ou agrupá-lo para que se estude seus atos, atividades, significados, relações, etc (TRIVIÑOS, 2006). Os aspectos observados foram registrados em um caderno de anotações e, durante o período de coleta, um pesquisador trabalhou como voluntário na instituição, auxiliando nas atividades da mesma.

c) Análise documental. Quanto a análise documental essa técnica envolve o estudo de documentos físicos e eletrônicos (TRIVIÑOS, 2006). Foram selecionados alguns documentos cedidos pela organização, nomeadamente apresentações, relatórios, páginas da web, estatutos e normas.

Com relação a a análise dos dados utilizamos a técnica de análise de conteúdo, a saber:

[...] um conjunto de técnicas de análise das comunicações, visando, por procedimentos sistemáticos e objetivos de descrição do conteúdo das mensagens, obter indicadores quantitativos ou não, que permitam a inferência de conhecimentos relativos às condições de produção/recepção (variáveis inferidas) das mensagens. (BARDIN, 1977, p. 42).

Segundo Minayo e Sanches (1999) a análise de conteúdo é desenvolvida em três fases: i) organização do material coletado; ii) definição das unidades de registro, de contexto e trechos significativos para as categorias; e iii) tratamento quantitativo e tendências dos fenômenos analisados.

Portanto, na primeira fase organizamos todo o material coletado em ficheiros de áudio, para que depois fossem transcritos e registrados os documentos, utilizando o MaxQDA e Word. Nas observações, utilizamos um caderno de anotações para registrar os acontecimentos diários e esses foram resgatados na próxima fase para a codificação. Os documentos também foram separados em "Documentos Institucionais $\left(\mathrm{n}^{\mathrm{o}}\right)$ " para que fossem categorizados e analisados.

$\mathrm{Na}$ segunda fase, continuamos com o programa suporte para a análise de dados qualitativos, elencamos as categorias criadas no software e definimos os trechos selecionados para cada codificação utilizada. Desta forma, separamos os trechos das entrevistas pelas categorias do processo descritivo.

Destacamos que na análise utilizamos a nomenclatura "Entrevistado $\left(\mathrm{n}^{\mathrm{o}}\right)$ " para referir as entrevistas com os colaboradores das organizações e que, no âmbito da análise de conteúdo, optamos por utilizar somente a orientação qualitativa, uma vez que a perspectiva quantitativa restringia uma análise mais dinâmica e flexível dos dados. Desta forma, utilizamos o material empírico coletado em conjunto com os referenciais teóricos disponíveis para verificar contradições e compreender os fenômenos estudados (DELLAGNELO, SILVA, 2005). Procuramos confrontar os dados encontrados nas organizações estudadas com as teorias da 
inovação social, com o objetivo de clarificar convergências e divergências entre eles, ou seja, uma análise entre teoria e prática.

\section{A INOVAÇÃO SOCIAL DO SAÚDE CRIANÇA FLORIANÓPOLIS}

O Saúde Criança Florianópolis, nasceu no ano de 2008 com o nome de Associação Saúde Criança Recontar. No ano de 2010 ela tornou-se a primeira franquiada do Saúde Criança, passando a se chamar Saúde Criança Florianópolis. Além de Florianópolis associação também atende famílias da meso região como São José, Palhoça e Biguaçu. A associação utiliza a metodologia Plano de Ação familiar, criada no Rio de Janeiro, para o desenvolvimento de suas atividades. Essa inovação social que analisamos nessa pesquisa, baseia-se em cinco dimensões: renda (econômica), saúde, educação, moradia (habitação) e cidadania (sócio política).

A primeira dimensão, renda (econômica) visa proporcionar as famílias uma base para o auto sustento e independência delas, dando cursos profissionalizantes como artesanato, manicure e artesanato, conforme cada interesse. A organização possui como meta em inserir um adulto na família no mercado de trabalho e que se consiga $1 / 4$ de salário mínimo por membro da família.

A saúde é a segunda dimensão estudada nessa pesquisa. O objetivo da organização é acompanhar em média 18 crianças e 16 atendimentos homeopáticos por mês. No SCF esse trabalho era realizado através do acompanhamento gratuito por psicólogos, médicos, nutricionistas, assistentes sociais e fisioterapeutas nas 40 famílias estudadas. Além disso, também há a doação de alimentos, remédios e aparelhos médicos.

A terceira dimensão da metodologia $\mathrm{PAF}$ envolve aspectos relacionados à educação. $\mathrm{O}$ objetivo desse apoio é que as famílias que não tenham o ensino fundamental e ensino médio consigam retornar e terminar esses estudos. Ressalta-se que a organização também procura acompanhar a evolução escolar das crianças e conscientizar as famílias a estudar e lerem livros.

A quarta dimensão envolve aspectos da melhoria da moradia (habitação). O principal objetivo é que a família tenha um local digno para se morar que não afete negativamente a saúde das famílias. Como meta a organização coloca que a residência deve ter no mínimo dois cômodos e condições sanitárias básicas.

O último aspecto refere-se a cidadania. Esse apoio tem como objetivo solucionar questões jurídicas e garantir acesso aos direitos básicos que o Estado pode fornecer para as 
famílias. A meta estipulada é que os participantes estejam com documentos básicos em dia e que sejam assíduas nas palestras socioeducativas promovidas pelo SCF.

O objeto de análise desta pesquisa está centrado na inovação social, que se materializa numa metodologia de ação (Plano de Ação Familiar) explicada nos parágrafos anteriores. Essa metodologia foi criada, num primeiro momento, no Saúde Criança Matriz (Rio de Janeiro) e adaptada nas diversas organizações do Brasil. Apesar do território de análise abranger a cidade de Florianópolis e sua mesorregião ampliaremos a análise, em alguns momentos, para o Saúde Criança Matriz, pelo fato da metodologia ter sido criada lá. Além disso, também alargaremos a análise para as atividades envolvidas na associação de Florianópolis, pois a ferramenta desenvolvida abrange áreas que vão além da descrição da inovação social.

A primeira categoria, o contexto inicial, visa identificar qual foi a conjuntura que resultou no surgimento da inovação social. Existem diversos fatores que podem levar ao nascimento de uma inovação social. Particularmente o Plano de Ação Familiar nasceu de um problema social: Eu acho que é bastante inovador porque começou com a percepção que existia um ciclo vicioso, miséria, internação, reinternação e morte. O ato médico nos hospitais públicos não faz sentido. A pneumonia, por exemplo, é a ponta do iceberg. Por trás chove dentro da casa, a casa está em risco, a mãe está desempregada, têm mais quatro irmãos, todos fora da escola. (Documentos Institucionais 1).

Podemos dizer que existia (e ainda existe) um problema social, que era o ciclo de miséria, internação, reinternação e morte nos hospitais públicos. Assim, a diretora da organização, verificou que "a maior causa da doença é a miséria, são as condições de vida que os pacientes vivem. Então não adianta você fazer uma abordagem médica tradicional, se você não interferir e transformar as condições de vida nas crianças e mulheres de baixa classe no Brasil.” (Documentos Institucionais 1).

Portanto, a diretora queria que a medicina tivesse uma abordagem integrada e que o trabalho desenvolvido por ela e pelos seus parceiros fosse além do que o serviço público podia fazer.

O contex to inicial surgiu por meio de um problema social, no entanto, como a fundadora desejava criar uma abordagem integrada, a situação inicial fez com que ampliassem a sua dimensão social, abrangendo também a educação além da saúde, e integrou no seu cerne a resolução de situações econômicas (renda, trabalho, profissionalização e habitação) e políticos (cidadania). 
Assim, com intuito de resolver este ciclo de miséria e oferecer um serviço de medicina integrada, a fundadora desenvolveu em 1991 a Associação Saúde Criança, uma organização sem fins lucrativos que é centrada na sua metodologia de atuação, o Plano de Ação Familiar, representada por uma mão que simboliza cinco campos de ação: "Então, essa mãozinha, ela simboliza os 5 eixos, a saúde, a moradia digna, a educação, a cidadania plena e a profissionalização para geração de renda”. (Entrevistado 1).

Desta forma, podemos novamente dizer que a materialização da inovação social é constituída pelo Plano de Ação Familiar desenvolvido primeiro no Saúde Criança Matriz e depois replicado nas filiais. O plano de ação, geralmente dura dois anos, (dependendo do caso pode durar mais que esse período) sendo que, num processo de discussão participativo entre as assistentes sociais, é decidido se a família está suficientemente autonomizada conforme os cinco critérios do PAF. A inovação social é instituída, portanto, como um processo organizacional que visa a inclusão social de famílias com crianças com alguma patologia crônica. Assim, reforça-se particularmente a ideia de que o PAF visa a mudança social mediante a transformação das relações de poder e essa mudança está intimamente associada com as inovações sociais de processo.

Após a maturação da Inovação Social, o Saúde Criança acabou por se expandir a diferentes estados no Brasil com a criação de filiais sociais. Desta forma, a sua atuação expandiu-se do nível micro (território do Rio de Janeiro), para um grau meso (sete filiais no Brasil) e, por fim, para uma abordagem Global (Saúde Criança New York e Berlim).

Particularmente em Florianópolis, a organização foi fundada em 2008 com o nome de Associação Recontar. O pensamento no início, segundo o Entrevistado 3 era que "as demais organizações utilizassem a metodologia, mas que fossem totalmente autônomas em suas atividades.” Todavia, no ano de 2010 essa abordagem mudou e o Saúde Criança Matriz decidiu apoiar as organizações "oferecendo apoio financeiro (inicial) para a criação da nova filial, que formassem uma rede de contatos entre elas e que houvesse uma padronização na comunicação e exposição da marca Saúde Criança." (Entrevistado 3). Assim, no ano de 2010, a Recontar tornou-se a primeira filial do Saúde Criança, passando a chamar-se Saúde Criança Florianópolis.

No que toca o contexto inicial do SCF, observamos que foi semelhante ao verificado no Rio de Janeiro, o desejo de resolver um problema social, econômico e político na região. No entanto, mais do que esses três desejos, havia um mote existencial para a criação da filial de Florianópolis. Uma das fundadoras tinha um sonho de criar uma organização social na 
América Latina e, para isso, construiu uma fundação para arrecadar dinheiro: "A gente tinha esse sonho de compartilhar fazendo um trabalho assim [associativo], na América Latina. E, então, eu falei: bom, eu vou abrir uma fundação e essa fundação vai receber esse dinheiro, e daí a gente pode decidir o que fazer." (Entrevistado 2).

No entanto, o pensamento inicial da idealizadora do Saúde Criança Florianópolis era abrir uma associação no Peru, mas ela decidiu mudar de ideias por causa de um sonho que ela teve:

[...] eu pensei em voltar para o Peru, porque eu tinha morado lá e ele também (o falecido marido dela). Dai eu sonhei numa noite, bem profunda, bem vívida, ele veio para mim e meu marido estava ali e ele falou: eu tenho o maior prazer de ter que vir para o Brasil. E no dia seguinte eu falei para todo mundo: eu não estou indo para o Peru não, estou indo para o Brasil. E pronto, vou fazer meu Saúde Criança, mas eu não sabia aonde. Eu não queria voltar para o Rio. (Entrevistado 2).

A escolha de montar uma filial do Saúde Criança ocorreu por dois motivos. O primeiro, era existencial, para dar continuidade aos trabalhos que o falecido marido fazia, já que ele era um dos conselheiros do Saúde Criança Matriz. Segundo, observou-se um mote social, pois a metodologia era teoricamente muito semelhante ao que ela estava estudando no seu doutorado.

E com um ano que ele faleceu, quando a gente estava no Rio, ele era conselheiro da Saúde Criança Matriz. E o meu marido também gostava muito [do Saúde Criança]. E até o momento da morte dele, ele era conselheiro. [...] [O Saúde Criança] era algo que tinha comigo, algo que tinha com ele. E quando eu estava fazendo o doutorado, quando eu estava fazendo o projeto, eu estava lendo bastante sobre o combate do problema de saúde infantil. E eu estava vendo e era muito parecido com o Saúde Criança. Assim, em teoria pelo menos. Mas, tinhas muitas partes que batia com o Saúde Criança. [...] tinha a ver com meu doutorado, com meus interesses. (Entrevistado 2).

Com relação ao objetivo da inovação social podemos dizer que, no âmbito teórico, a inovação social visa a satisfação das necessidades humanas não atendidas nem pelo Estado, nem pelo mercado, o empoderamento de atores e a mudança de relações (criação de novos laços) em diferentes grupos da sociedade (MOULAERT et al., 2005; Comissão Europeia, 2005; ANDRÉ, ABREU, 2006; MOULAERT, 2009, 2010; DEFOURNY, NYSSENS, 2013).

A atuação do Saúde Criança no atendimento das necessidades humanas é orientada para realização de atividades complementares à atuação do Estado, especificamente por meio do preenchimento de lacunas temporariamente deixadas por este. No discurso do Entrevistado 2 é possível compreender com mais clareza a atuação da organização:

A gente complementa sempre onde têm buracos, por exemplo, a gente tem o direito ao leite especial, o objetivo do Saúde Criança não é "Ah, vamos dar leite especial sempre para essa família”, a gente vai dar esse direito enquanto o governo não fornece à essas pessoas, mas sempre de uma forma à curto prazo, porque tem um buraco no Estado, algo que ele deveria estar fazendo. Nós oferecíamos dentistas particulares quando os dentistas deles (do Estado) não estavam atendendo, mas não 
é o nosso objetivo, mas sim educação em termos bucais. Tem muito mais a ver como você chega até o dentista na sua localidade, se não tem dentista você pede isso no posto de saúde, ou como você encontra através da universidade, tem um monte de cursos aqui, só é preciso ir atrás, e encontrar essa vontade. (Entrevistado 2).

Portanto, verifica-se que o objetivo da organização não passa pela substituição dos serviços de responsabilidade estatal, ainda que ofereça recursos e serviços para atender necessidades temporárias e pontuais de seus participantes. O foco do Saúde Criança é voltado para o fomento ao exercício da cidadania, ao ensejar que os indivíduos tenham as informações e orientações necessárias para buscar por si próprios os meios para o atendimento de suas necessidades. Em outras palavras, para que conheçam os seus direitos e possam reivindicá-los de forma autônoma.

Neste sentido, procuramos nos discursos dos Entrevistados expressões que corroborassem com o desenvolvimento de ações nesse sentido. O Entrevistado 3 relatou que a organização exerce um papel importante para que os seus beneficiários conheçam os seus direitos: Acho que muitas famílias que chegam no Saúde Criança não conhecem os direitos que possuem. Então, eles passam a conhecer, porque a próprias assistentes sociais passam (informam) os direitos deles. Vale ressaltar que o conhecimento dos direitos é um aspecto essencial para que os indivíduos possam exercer a sua cidadania ativamente, que é o cerne do empoderamento e da autonomia.

Para além do fomento à cidadania enquanto apropriação dos diretos, a instituição atua no sentido criar melhores condições de vida para os seus beneficiados num sentido holístico, ou seja, a sua metodologia visa o empoderamento mediante a integração de eixos como o econômico, psicológico (saúde), habitacional e educacional.

O último aspecto que uma inovação social almeja é a mudança dos laços sociais. Segundo uma das beneficiadas, pode-se verificar que o PAF possibilita, além do autoreconhecimento e empoderamento, o desenvolvimento de novos laços sociais: "eu aprendi bastante coisas, eu aprendi bastante nas oficinas. Os médicos me ensinou e ajudou bastante coisa com o problema de minha filha, diminuiu o número de convulsões, estão bem controladas. Eu fiz amizade com o pessoal daqui.” [sic] (Beneficiado 1).

No âmbito econômico, também observamos que ocorre a criação de novos laços através do projeto Eu Faço. Caso necessite, ao sair da organização, a mãe da criança tem a possibilidade de voltar a trabalhar com artesanato, portanto ela consegue manter o seu vínculo com o projeto de capacitação profissional, com feiras de venda de produtos feitos a mão e com as outras famílias que foram beneficiadas pelo Saúde Criança: Ela fica dois anos e se forma, então essa 
INOVAÇÃo

mãe quando ela sai já sabe fazer tudo que eu faço, ela já foi fazer feira comigo, né? Ela já aprendeu a apresentar o Saúde Criança na feira, ela aprendeu a vender o produto. Então, essas mães eu convido que quer voltar a trabalhar, para conseguir continuar a produção (Entrevistado 4).

A dimensão objetivo também ultrapassa a barreira da metodologia e penetra nas práticas e valores organizacionais. Mesmo com a profissionalização da gestão da associação, os seus preceitos continuam enraizados, como cita o Entrevistado 2: "E eu colocaria também uma outra coisa, uma coisa humana. Então, eu tenho essa sensação que a gente seja um lugar muito forte, que as pessoas gostam de vir, as pessoas que trabalham, voluntários, eu acredito que é um lugar com muito amor por todos os lados, não só para as famílias, mas também para os funcionários, para os voluntários, para todo mundo. Tá todo mundo envolvido [...] eu vi que houve uma inclusão social dos dois lados, então é todos nós se sentindo incluindo e não só a família, somos todos nós se sentindo parte de uma coisa só. Em cada momento cada um de nós recebe e dar, todos nós as familias recebem e dão, a gente recebe e dá. "[sic].

Recapitulando, podemos dizer que a metodologia do Plano de Ação Familiar é uma inovação social, porque visa satisfazer as necessidades humanas não atendidas pelo Mercado nem pelo Estado, o empoderamento individual e coletivo, e as mudanças das relações sociais a partir da criação de novos laços. Também verificamos que a organização trabalha com valores de reciprocidade.

O seu nascimento aconteceu pelo desejo de responder à problemas sociais, econômicos, existenciais e políticos da região, mas que logo foi se expandindo para vários estados no Brasil e outros países (com fundos internacionais).

\section{CONCLUSÕES}

A inovação social tem como seus principais objetivos satisfazer as necessidades humanas, por vezes, não atendidas nem pelo Estado, nem pelo mercado, empoderar atores sociais excluídos e que se encontram privados de determinados bens, mudar as relações sociais de poder e promover a inclusão social (MOULART et.al., 2005). Ela encontra um ambiente favorável à sua expressão nas organizações da economia solidária, dado que compartilham de valores e objetivos.

Uma inovação social pode se originar em diversos contextos e dinâmicas. Entretanto, espaços marcados pela exclusão social, nas quais variáveis como emprego, moradia e cidadania 
são deficitários, tornam-se, especialmente, caros ao surgimento de inovações que visam promover modificações positivas no cenário predominante.

Ademais, a privação de necessidades humanas fundamentais, nomeadamente, material (comida, roupa e abrigo), social (educação e saúde), existencial (liberdade de expressão e criativa) e política (cidadania ativa) constituem-se também como elementos motivadores das inovações sociais (GONZALEZ et al., 2010). Portanto, uma inovação social nasce por diferentes contextos inciais, como sociais, econômicos, existenciais, políticos e, também, podese refletir que os aspectos ambientais também catalizam o surgimento desse tipo particular de inovação.

No caso do Plano de Ação Familiar do Saúde Criança, o contexto de surgimento da inovação social deriva de um problema social, especificamente, um ciclo de miséria, internação, reinternação e morte nos hospitais públicos, que afetava - e ainda afeta - uma parcela significativa da população, e que, no caso estudado, não tinha encontrado formas efetivas de enfrentamento em âmbito estatal e mercadológico.

Com vistas a desenvolver uma abordagem integrada para confrontar essa problemática, as dimensões inovativas transcenderam o âmbito social no Saúde Criança, e passaram a abranger também a educação além da saúde, e integrou no seu cerne a resolução de situações econômicas, tais como renda, trabalho, profissionalização e habitação, e políticos (cidadania).

A inovação social é instituída, portanto, como um processo organizacional que visa a inclusão social de famílias com crianças com alguma patologia crônica, por meio de uma abordagem holística e integrada, englobando esferas essenciais da vida humana.

Embora este estudo de caso possa fornecer alguns indicativos sobre as configurações da inovação social em sua expressão enquanto prática organizacional, o campo ainda carece de estudos capazes de contribuir de forma robusta para o entendimento e delineamento de formas de gestão da inovação social, a sua materialização e seu efetivo impacto. Portanto, é uma vasta área a ser explorada por novas pesquisas e perspectivas.

\section{REFERÊNCIAS}

ANDRÉ, I., ABREU, A. (2006). Dimensões e espaços da inovação social. Finisterra, XLI(81), 121-141.

BARDIN, L. (1977). Análise de conteúdo. Lisboa: Edições. 
BIGNETTI, L. P. (2011). As inovações sociais: uma incursão por ideias, tendências e focos de pesquisa. Ciências Sociais Unisinos, 47(1), 3-14. doi:10.4013/csu.2011.47.1.01

BOUCHARD, M. J. (2011). Social innovation, an analytical grid for understanding the social economy: the example of the Quebec housing sector. Service Business, 6(1), 47-59. doi: $10.1007 / \mathrm{s} 11628-011-0123-9$

Bureau of European Policy Advisers (BEPA). (2011). Empowering people, driving change: social innovation in the European Union. Luxemburgo: Publications Office of the European Union.

CLOUTIER, J. (2003). Qu'est-ce que l'innovation sociale?. Montréal: CRISES.

COSTA, P., \& CARRION, R. (2009). Situando a economia solidária no campo dos estudos organizacionais. Revista Latino Americana de Economía Social y Solidaria, 3(4), 66-81.

COUTO, Ana Isabel; SANTOS, Mónica; GUERRA, Paula. (2012). A Importância da economia solidária na promoção da coesão social: breve reflexão a partir do caso português. Boletim Mercado De Trabalho, 52, Brasília, IPEA.

CRISES. (2015). Centre de Recherche sur les Innovations Sociales. Recuperado de http://www.crises.uqam.ca/

DEES, G., Anderson, B.B.; WEI-SKILLERN J. (2004). Strategies for Spreading Social Innovations. Stanford Social Innovation Review, p. 23-32.

DEFOURNY, J., \& NYSSENS, M. (2013). Social innovation, social economy and social enterprise: what can the European debate tell us? In The International Handbook on Social Innovation: Collective Action, Social Learning and Transdisciplinary Research (1ed., Vol. 1, pp. 40-52).

DELLAGNELO, E. H. L., SILVA, R. C. da. (2005). Análise de conteúdo e sua aplicação em pesquisa na administração. Pesquisa qualitativa em Administração. Rio de Janeiro: Editora FGV. 
FRANÇA FILHO, G. C. de. (2001). A problemática da economia solidária: uma perspectiva internacional. Sociedade e Estado, 16(1-2), 245-275

GABOR, D. (1970). Innovations: Scientific, Technological and Social (1 ed). Oxford: Oxford University Press.

GAIGER, L. I. (2007). A outra racionalidade da economia solidária. Conclusões do primeiro mapeamento nacional no Brasil. Revista Crítica de Ciências Sociais, 79.

GODOY, Arilda Schmidt. (1995). Pesquisa Qualitativa: tipos fundamentais. São Paulo, SP: $R A E, 35(3), 20-29$, mai/jun.

GONZALEZ, S., FRANK, M., \& MARTINELLI, F. (2010). ALMOLIN: How to analyse social innovation at the local level? In Can Neighbourhoods Save the City? Community development and social innovation (1ed., Vol. 1, pp. 49-67). New York: Routledge.

JESSOP, B., MOULAERT, F., HULGARD, L., \& HAMDOUCH, A. (2013). Social innovation research: a new stage in innovation analysis? In The international handbook on Soial Innovation: collective action, social leraing and transdisciplinary research (1ed, Vol. 1, p. 110-130). Reino Unido: Edward Elgar Publishing, Inc.

LAVILLE, J. L. (2014) Economia Solidária. Conferência ISCTE: Lisboa.

MINAYO, Maria Cecilia de S., SANCHES, Odécio. (1999). Quantitativo-Qualitativo: oposição ou complementaridade? Rio de Janeiro: Caderno de saúde pública. 9, 239-262 jul/set.

MOULAERT, F., \& AILENEI, O. (2005). Social economy, third sector and solidarity relations: a conceptual synthesis from history to present. Urban studies, 42(11), 2037-2053.

MOULAERT, F., MARTINELLI, F., SWYNGEDOUW, E., \& Gonzalez, S. (2005). Towards alternative model (s) of local innovation. Urban Studies, 42(11), 1969-1990. 
MOULAERT, F. \& NUSSBAUMER, J. (2006). L'innovation sociale au coeur des débats publics et scientifiques: un essai de dé privatisation de la société, In: Klein, J. L. (Ed.) L' Innovation Sociale. Ste-Foye: Presses Universitaire du Québec.

MOULAERT, F. (2009). Social Innovation: Institutionally Embedded, Territorially (Re)Produced. In D. MacCallum, F. Moulaert, J. Hillier, \& S. V. Haddock (Orgs.), Social innovation and territorial development (p. 11-24). Farnham, Inglaterra; Burlington, VT: Ashgate.

MOULAERT, F. (2010). Social innovation and community development: concepts, theories and challenges. In F. Moulaert, F. Martinelli, E. Swyngedouw, \& S. Gonzalez (Orgs.), Can neighbourhoods save the city? community development and social innovation (p. 4-16). London: Routledge.

MULGAN, G., TUCKER, S., ALI, R., SANDERS, B. (2007). Social Innovation: what it is, why it matters and how it can be accelerated. Londres: The Basingstoke Press.

MURRAY, R., CAULIER-Grice, J., MULGAN, G. (2010). The open book of social innovation. National endowment for science, technology and the art. Recuperado de http://blog.eisco2012.eu/home/european/library/literature/Social_Innovator_020310.pdf

NEAMTAM, Nancy. (2002). The Social and Solidarity Economy: Towards an 'Alternative' Globalization (A. Mendell, Trans.). Artigo apresentado no simpósio "Citizenship and Globalization: Exploring Participation and Democracy in a Global Context," Langara College, Vancouver, June 14-16, 2002. Recuperado de: http://www. shatil.org.il/files/socialsolidarity\%20economy.pdf

NESTA. (2014). Nesta. Recuperado de: http://www.nesta.org.uk/. Reino Unido: Edward Elgar Publishing, Inc.

RICHARDSON, Roberto Jarry. (2007). Pesquisa Social: métodos e técnicas. 3 ed. São Paulo, SP: Atlas.

TARDE, G. (1999). [1893]. La logique sociale, Paris: Synthélabo.

TAYLOR, J. B. (1970). Introducing Social Innovation. The Journal of Applied Behavioral Science, 6(1), 69-77. http://doi.org/10.1177/002188637000600104 
THE YOUNG FOUNDATION (YF). (2010). Study on SI. Report prepared by the Social Innovation exchange (SIX) and the Young Foundation for the Bureau of European Policy Advisors.

TRIVIÑOS S. N. Augusto. (2006). Introdução à pesquisa em ciências sociais: a pesquisa qualitativa em educação. São Paulo, SP: Atlas.

YIN, Robert K. (2010). Estudo de caso: planejamento e métodos. 4. ed. Porto Alegre: Bookman. 


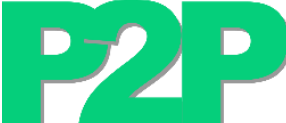

? INOVAÇão 